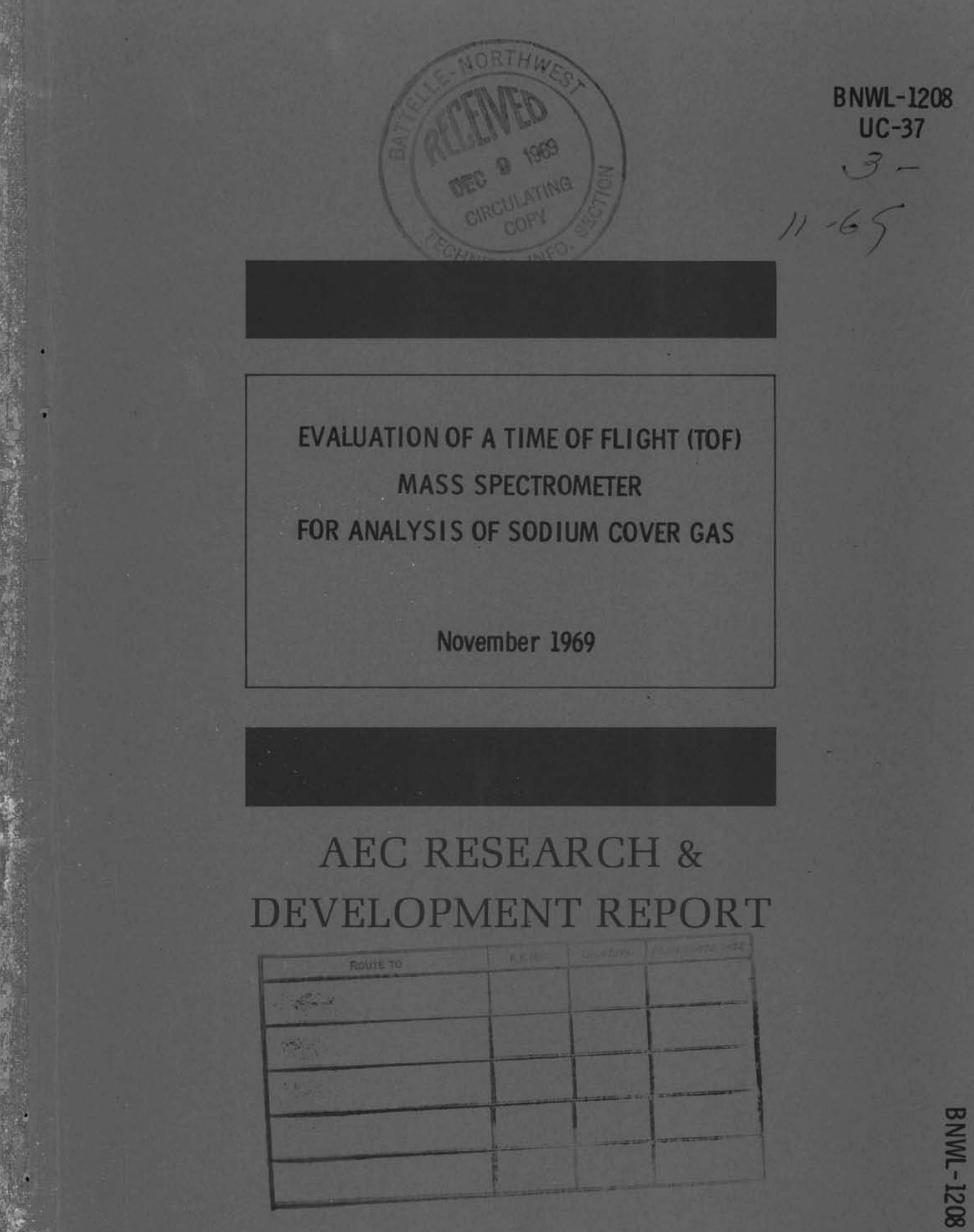




\section{LEGAL NOTICE}

This report was prepared os an account of Government sponsored work. Neither the United States, nor the Commission, nar any person acting on behalf of the Commission:

A. Makes any warranty or representation, expressed or implied, with respect to the accuracy, completeness, or usefulness of the information contained in this report, or that the use of any information, apparatus, method, or process disclosed in this report may not inftinge privately owned rights; or

B. Assumes any liabilities with respect to the use of, or for damages resulfing from the use of any information, apparatus, method, or process disclosed in this report.

As used in the above, "person acting on behalf of the Commission" includes any employee or contractor of the Commission, or employee of such confractor, to the extent that such employee or contractor of the Commission, or employee of such contractor prepares, disseminates, or provides access to, any information pursuant 10 his employment or contract with the Commission, or his employment with such contractor.

\section{PACIFIC NORTHWEST LABORATORY RICHLAND, WASHINGTON \\ operated by}

BATTELLE MEMORIAL INSTITUTE

for the

UNITED STATES ATOMIC ENERGY COMMISSION UNDER CONTRACT AT(45-1)-1830 


\title{
EVALUATION OF A TIME OF FLIGHT (TOF) MASS SPECTROMETER FOR ANALYSIS OF SODIUM COVER GAS
}

By

\author{
G. B. B a r to n \\ Sodium Chemistry Department \\ Chemistry and Metallurgy Division
}

November 1969

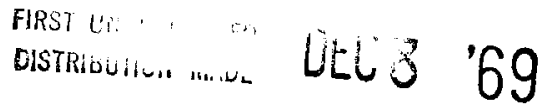

BATTELLE MEMORIAL INSTITUTE

PACIFIC NORTHWEST LABORATORIES

RICHLAND，WASHINGTON 99352 
BNWL -1208

Printed in the United States of America Available from

Clearinghouse for Federal Scientific and Technical Information National Bureau of Standards, U.S. Department of Commerce Springfield, Virginia 22151

Price: Printed Copy $\$ 3.00 ;$ Microfiche $\$ 0.65$ 


\section{EVALUAT I ON OF A TIME OF FLIGHT (TOF) MASS SPECTROMETER FOR ANALYSIS OF SODIUM COVER GAS}

\section{G. B. Barton}

\section{ABSTRACT}

The limiting sensitivity of the TOF mass spectrometer, found to be $5 \pm 5$ ppm for methane and hydrogen, was considered adequate for FFTF sodium cover gas analyses. However, certain difficulties in the routine operation and in the introduction of high temperature, sodium bearing samples were considered to render this instrument less effective than a gas chromatograph as a continuous monitor. 


\section{TABLE OF CONTENTS}

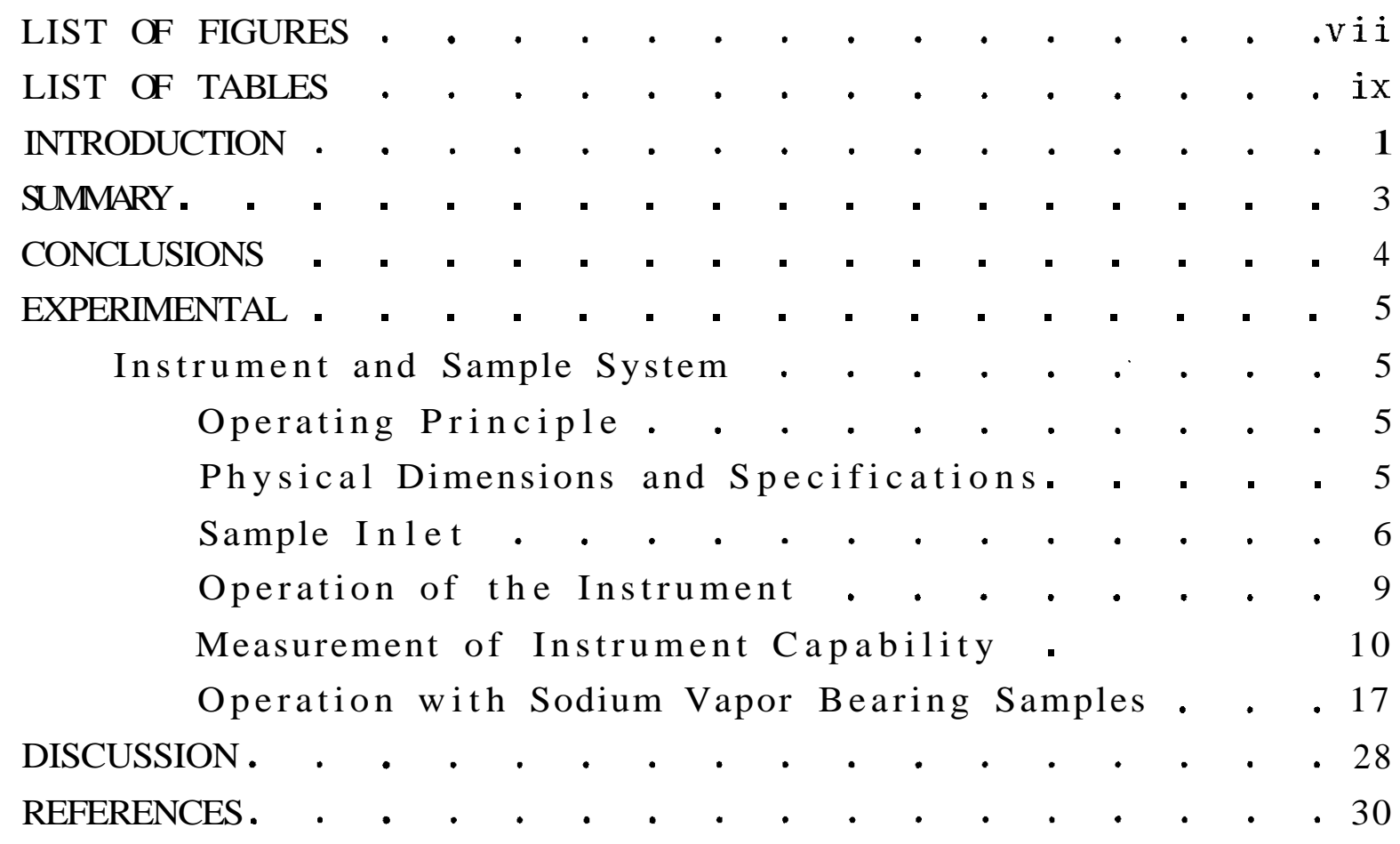




\section{LIST OF FIGURES}

1 Continuous Flow Inlet System to Mass Spectrometer

2 Schematic Arrangement of Gas Flow Through and Around Sodium Bearing Capsule

3 Original Resolution of Instrument

Changes in Peak Height Ratio Versus Dilution of $1000 \mathrm{ppm}$ Mixture of $\mathrm{CH}_{4}$ with Additional Argon

5 Changes in Peak Height Ratio Versus Dilution of $100 \mathrm{ppm}$ Mixture of $\mathrm{CH}_{4}$ in Argon with Additional Argon

6 Changes in Peak Height Ratio Versus Dilution of $100 \mathrm{ppm}$ Mixture of $\mathrm{H}_{2}$ in Argon with Additional Argon

7 Continuous Record of Ion Current from Mass 2 and Mass 36 


\section{LIST OF TABLES}

1 Preliminary Tests of Sensitivity

2 Change in Peak Height With and Without Liquid Nitrogen Trap Operating

3 Peak Height Ratio Versus Dilution

4 a Constancy of Peak Height and Peak Height Ratio of Argon and $1000 \mathrm{ppm}$ Methane (Peak heights normalized to 10-11 Amp)

4b Constancy of Peak Height and Peak Height Ratios of Tank Argon Sample (Electrometer range $3 \times 10^{-10}$ Amp)

$5 \quad$ Variation in $36 / 40$ Ratio

6 Effect of Passing Methane-Argon Mixture Through Sodium Containing Capsule

7 Reduction at Hydrogen Peak by Liquid Nitrogen Trapping 
BNWL -1208

\section{EVALUAT I ON OF A TIME OF FL I GHT (TOF) MASS SPECTROMETER FOR ANALYSIS OF SODIUM COVER GAS}

G. B. Barton

INTRODUCTION

Argon has been chosen as the cover gas for the sodium system of the FFTF. (1) The contamination of argon with reactive gases can have deleterious effects on the sodium or the materials in contact with the sodium such as fuel cladding or sodium containment materials. The reactive gases of concern are mainly those from air leakage and carbonaceous gases such as carbon dioxide, carbon monoxide, and hydrocarbons which may be introduced through the addition of organic materials. Hydrogen, generated by the reaction of water or hydrocarbons with the hot sodium, is also a potential problem. The permissible concentration limits for these gases in the argon have not been firmly fixed, but preliminary estimates of allowable concentrations have been made. (2) The allowable concentrations at the anticipated FFTF operating temperatures are of the order of $10 \mathrm{ppm}$. Therefore, a method of measuring the concentration of these impurities is needed. To be useful, this method must have a sensitivity of better than $10 \mathrm{ppm}$. In addition to sufficient sensitivity, any method for analyzing the reactive impurities in the argon must be sufficiently selective to permit unequivocal measurement of the individual chemical species.

The Time of Flight (TOF) Mass Spectrometer is known to have the selectivity required to meet all FFTF cover gas monitoring needs except those presented by a mixture of nitrogen and carbon monoxide. A nondispersive infrared analyzer can be used to measure carbon monoxide and thus resolve this pair. Therefore, evaluation of the applicability of the instrument has centered on the measurement of its sensitivity. 
The most promising general purpose alternative to the mass spectrometer is the gas chromatograph, previously found to have sufficient sensitivity. Each instrument has certain potential advantages. Those possessed by the mass spectrometer are: (1) the capability of detecting all substances present in significant concentrations in the sample and (2) the potential ability to analyze samples at the elevated temperatures of the system. This latter ability would minimize many of the problems associated with maintaining a representative sample during the cooling required by the chromatograph. Most of the sodium vapor is removed during this cooling and considerable potential exists for the scavenging of the impurities of interest by the removal process. A secondary objective of the evaluation program has been to establish the ability of the instrument to handle samples at or near system temperatures and to define the benefits attainable through this approach. 


\section{SUMMARY}

The small Bendix Time of Flight Mass Spectrometer was tested to determine (1) its sensitivity to hydrogen and methane in argon, and (2) the effects of sodium vapor bearing samples introduced into it at elevated temperatures. The sensitivity of this type mass spectrometer (at room temperature) has been measured to be $5 \pm 5$ ppm of hydrogen or methane in argon. At higher concentrations, the ratio of ion currents from impurity to that from the argon varied by less than $10 \%$ (standard deviation). Extraneous materials, such as from the sample lines, could be detected. There was no detectable difference in the methane concentration of a sample passing through heated lines to the instrument and one passing through room temperature lines. The background hydrogen level from heated lines and inlet was too high to permit detection of a 100-ppm addition. Special difficulties encountered in trying to introduce sodium vapor laden gas samples into the mass spectrometer included high background from the heated lines, leaks at fittings, and discrimination against sodium through the capillary sample splitter and molecular leak. 


\section{CONCLUSIONS}

- The TOF Mass Spectrometer sensitivity for meeting FFTF needs in the measurement of hydrogen and methane in argon cover gas is marginal. It is pushed to its limit to attain the required sensitivity.

- Using the peak height ratio technique, the instrument has sufficient precision and stability to meet FFTF cover gas monitoring needs.

- The instrument is sufficiently selective to meet FFTF cover gas monitoring needs when supplemented with data from a nondispersive infrared measurement of carbon monoxide.

- Contrary to expectations, little or no significant advantage results from the instrument's ability to analyze samples at system temperature. In fact, in the case of hydrogen, considerable difficulty is created by hydrogen from the hot sample lines.

- The knowledge and skill required to obtain optimum performance from the instrument is expected to over-burden reactor plant operators already occupied with their duties. Automatic operation under computer control may be feasible and could largely shift responsibility for monitoring satisfactory operation to instrument maintenance personnel.

- The gas chromatographic approach is better suited than the mass spectrometric approach to the in-line monitoring of FFTF cover gas impurity concentrations. 


\section{EXPERIMENTAL}

\section{INSTRUMENT AND SAMPLE SYSTEM}

The instrument examined was a small time of flight spectrometer built by the Bendix Corporation and designated as Model MA-1.

Operating Principle

The time of flight spectrometer obtains mass separation by accelerating bursts of ions to a uniform energy in an electric field. Ions of similar mass attain similar velocities (proportional to $\mathrm{M}^{1 / 2}$ ) and reach the detector in a group. A pulse of electrons generated by each group of ions striking the detector is collected and amplified to give a signal proportional to the number of ions. Control of the collection action by a timing circuit enables the ion current from any particular mass to be selected and measured. The ions are generated by a pulsed beam of electrons and are accelerated by a pulsed electric field at a frequency of $50 \mathrm{kHz}$. The instrument can monitor a single mass continuously or, by scanning any part of the mass range at any of 10 rates, can cover the mass range 2 to 200 in $1.5 \mathrm{sec}$ to $1 \mathrm{hr}$. The output can be displayed on an oscilloscope or fed to a strip chart recorder. Two output channels can be operated simultaneously for isotope ratio measurement.

$\underline{\text { Phvical Dimensions and Specifications }}$

The drift tube of the Bendix Model MA-1 instrument is $20 \mathrm{~cm}$ long compared with the one or two-meter lengths of their earlier instruments. The analyzer tube and vacuum system are mounted in a cabinet approximately $27 \mathrm{in}$. square. The electronics chasis, oscilloscope, and recorder nearly fill a standard 6-ft electronics cabinet. The manufacturer specifies the instrument as operable to $200{ }^{\circ} \mathrm{C}$ and capable of being baked out at $300{ }^{\circ} \mathrm{C}$, with unit resolution of 150 amu and sensitivity greater than 1 ppm. 
$\underline{\text { Sample Inlet }}$

The sample inlet system supplied with the instrument was designed for batch operation. Since the instrument was needed for continuous monitoring a flow type inlet system, shown schematically in Figure 1, was designed and built in our laboratory. It was designed to operate at sample temperatures up to $550{ }^{\circ} \mathrm{C}$. The mechanical vacuum pump of the spectrometer was connected to the inlet system. The sample splitting arrangement shown is necessary to enable the instrument to attain a reasonable speed of response to changes in sample composition and to permit the use of a molecular leak of readily attainable size. A sample splitting capillary of $0,0075 \mathrm{in.}$ ID was found to be too large, and one with an ID of approximately $0.004 \mathrm{in}$. was used. The gas flow through the smaller capillary was approximately $30 \mathrm{~cm}^{3} / \mathrm{min}$. The molecular leak was a stainless steel disc 0.002 in. thick containing four holes each approximately 0.0013 in. in diameter. With the mechanical vacuum pump valved out so there was atmospheric pressure on the upstream side of the molecular leak, the flow through it was about $3 \mathrm{~cm}^{3} / \mathrm{min}$. The flow into the spectrometer under operating conditions, although not measured, was much lower since the major part of the pressure drop occurred across the capillary.

In order to determine sensitivity of the instrument, a cylinder of mixed gases was connected directly to the inlet system. The system depicted schematically in Figure 2 was used for the investigation of the effects of sodium vapor and heated lines.

The instrument was supplied with a refrigeration system to cool a baffle and a trap above a mercury diffusion pump to $-35{ }^{\circ} \mathrm{C}$. Located above this pump was a liquid nitrogen trap designed for use in the event the refrigerated system should 


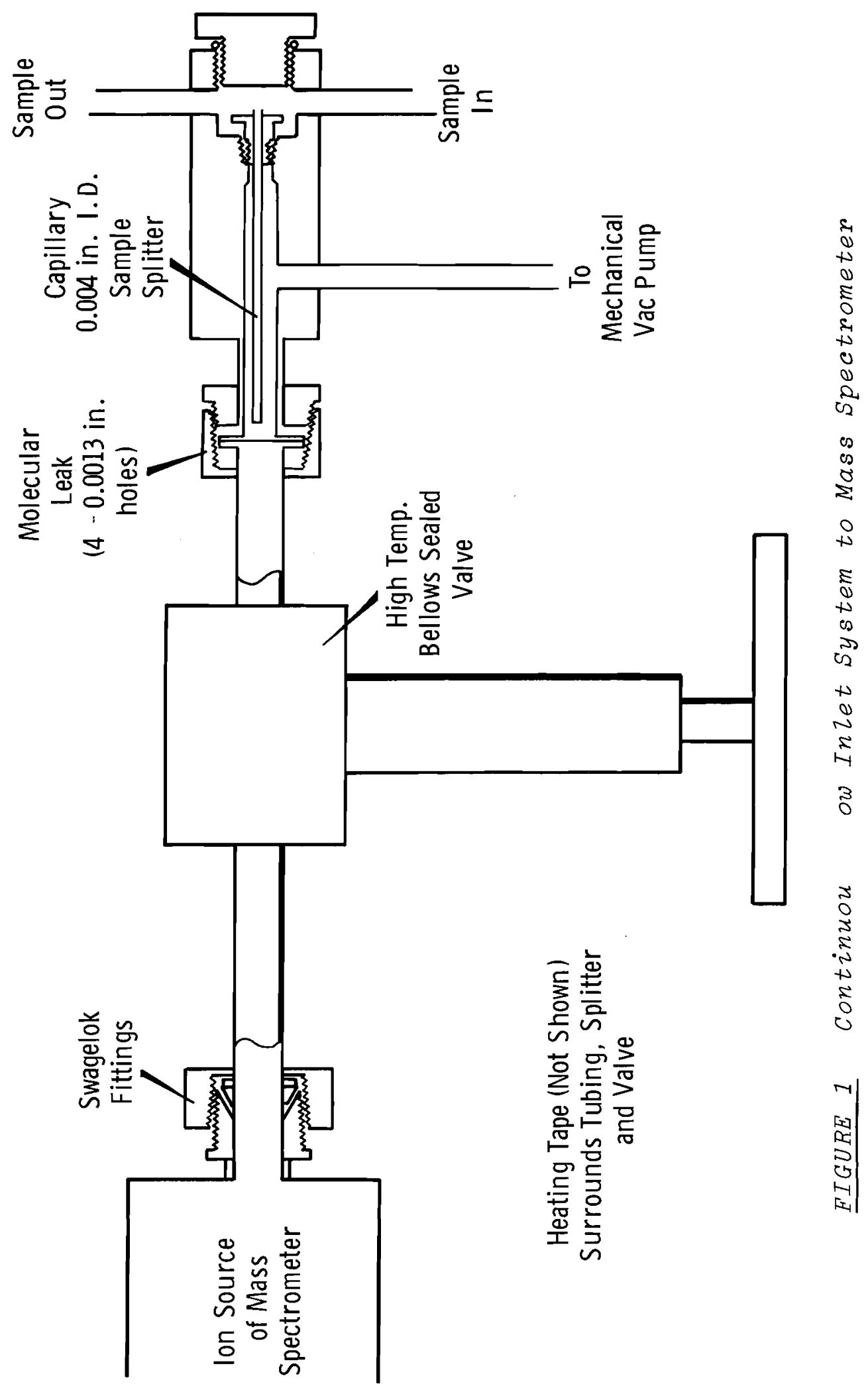




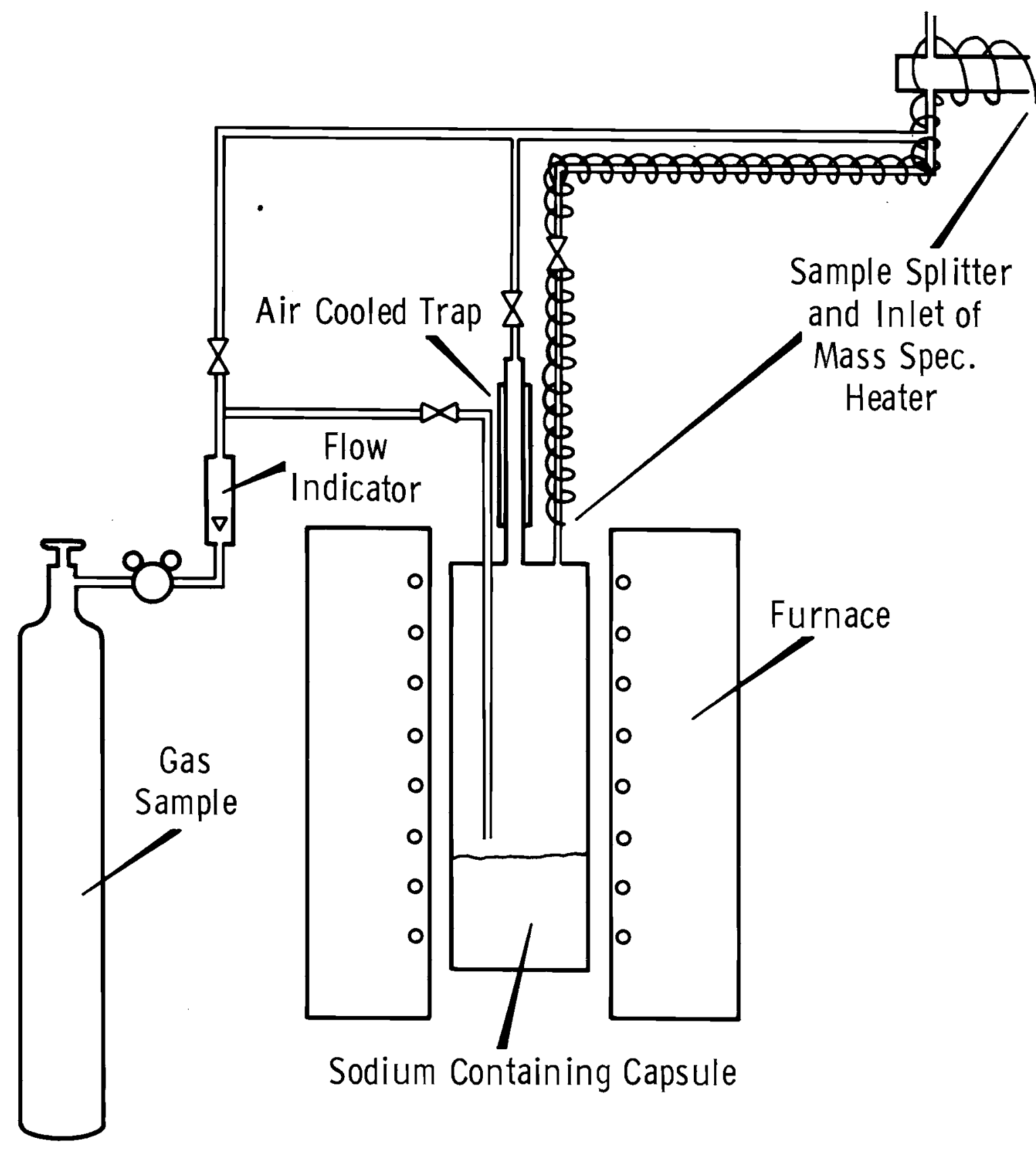

FIGURE 2. Schematic Arrangement of Gas Flow Through and Around Sodium Bearing Capsule 
fail to lower the pressure sufficiently. For operational reasons it is desirable to be able to operate without the liquid nitrogen trap cooled. Data are presented on measurements made with and without liquid nitrogen in the trap. Operation of the Instrument

Once the instrument was installed, it was pumped down to a pressure of less than $5 \times 10^{-5}$ torr and placed in operation. Operating variables were adjusted to give optimum resolution over the mass range of interest. These adjustments included: the collimating and compensating magnets controlling the direction of the electron beam in the ion source, the analyzer magnet position for maximum output from the detector, the electron energy, the ion focus potentiometer, the time lag focus potentiometer, and the high voltage controlling the gain of the detector. Control of the sensitivity of the electrometers measuring the ion current, and of the timing circuit selecting the mass to be measured is by step selector switch.

For process use, it is desirable that an instrument require only minimum readjustment following installation. This instrument was stable for weeks at a time during the first several months of operation. However, a loss of stability occurred with time and, before the measurements were finished, the periods of stable operation were less than $24 \mathrm{hr}$. Some effort to trace the source of the instability was not entirely successful. The only maintenance required during the several months of operation was an occasional cleaning of the electron multiplier section of the detector system and the replacement of the liner of the vacuum gage. The sample gases were clean and little trouble was encountered with the cold traps becoming heavily loaded. Trouble was experienced on two occasions with back diffusion of oil from the mechanical vacuum pump when accidents or maloperation shut down the mercury diffusion pump. 
BNWL -1208

Measurement of Instrument Capability

Figure 3, depicting an instrument background scan from mass 12 to mass 102, clearly shows the resolution to be good over the range of interest. Since the time of flight varies as the square root of the mass of the ion, resolution of adjacent masses decreases with increasing mass. At mass 28 , the valley is only $1 \%$ of the peak when the peak is full scale on the recorder. The initial measurements showed a substantial background in the instrument. Part of this background was found to result from leaks in the inlet. When these were corrected by installation of the continuous inlet, a significant background remained. Several months of operation, baking, and pumping were required to reduce it to a constant low level. A major part of the tenacious background was water held in the ceramic components of the analyzer tube.

One of the first indications that the ultimate sensitivity of the instrument was high was the separation and detection of the helium 3 isotope. Helium 3 has a natural abundance of $1.4 \mathrm{ppm}$. This is one of the most favorable cases to measure, however, and the ability of the instrument to measure small concentrations of the reactive gases in argon was of more concern.

The installation of the continuous inlet system made it impractical to calibrate by the classical method of measuring the ion current produced when pure gases at measured pressures are fed to the molecular leak of the spectrometer. An alternate calibration technique based on the use of prepared mixtures of impurity gases and argon was therefore employed. These mixtures were diluted in a dynamic system to produce a series of working standards with good relative values and moderately good absolute values. The first experiments with such a mixture employed one made to contain $1000 \mathrm{ppm}$ methane in argon. This mixture produced a ten-fold increase in the ratio of ion 
BNWL -1208

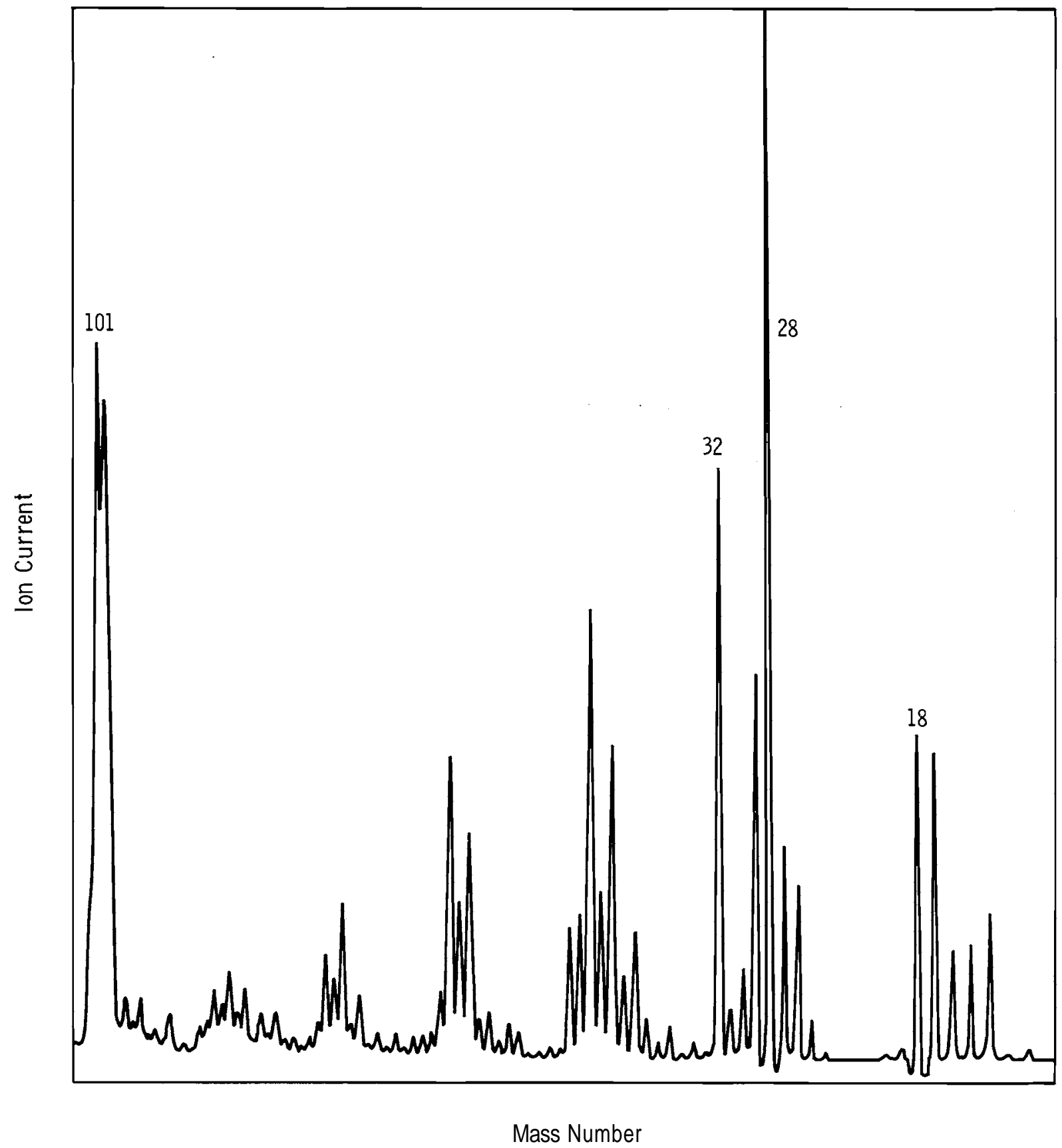

FIGURE 3. Original Resolution of Instrument 
currents for the 15 and 36 masses. A mixture of 90 ppm CO and $25 \mathrm{ppm}_{2}$ in argon gave a readily measurable increase in the $28 / 36$ ion current ratio, and a nominal mixture of 10 ppm of methane in argon produced a peak at mass 15 about three times the height of the noise trace (see Table 1). With these preliminary sensitivity measurements established, it was necessary to establish the linearity of the ion current, or more properly ion current ratio, with concentration changes. Before this could be done, it became necessary to shut the instrument down to clean the detector assembly. After reassembly, the system was baked and pumped until the water background was reduced to an acceptable level (less than the small 28 peak due to residual carbon monoxide and minute air leakage). To reduce the water to this level, it was necessary to operate with a liquid nitrogen trap. The instrument has a built-in refrigeration cooled trap that operates at $-35^{\circ} \mathrm{C}$. This trap is marginally adequate when the system is completely clean. Most of the time, however, the liquid nitrogen-cooled trap must be used to reduce the pressure to the point where the background does not interfere with the analysis of these low level samples (Table 2 shows the reductions effected by using the liquid $\mathrm{N}_{2}$ trap). This interference can act either to (1) produce ions of the same mass as those sought in the sample, or (2) remove ions by their collision with neutral atoms.

Linearity of response to change in sample concentration was established for the less than 1000 ppm range by starting with the nominal 1000 ppm methane in argon mixture and diluting it with argon. The peak height ratio data are presented in Table 3 and Figure 4. The data, although significantly scattered, lies along a straight line. Table 4a contains absolute ion current values measured during the methane calibration. The apparent variations are considerably greater than that observed for the peak ratios. This scatter results from short term unstability in the gain of the instrument. 
TABLE 1. Preliminary Tests of Sensitivity

Electrometer

Current To

Produce Full

Scale

Displacement,

Height at Peak Due to Mass, in.

Sample

$15 \quad 16 \quad$\begin{tabular}{llll}
18 & 28 & 32 & 36 \\
\hline
\end{tabular}
A

Argon
Argon +1000 pp
$\begin{aligned} \mathrm{Ar} & +25 \mathrm{ppm} \mathrm{O} \\ + & 90 \mathrm{ppm} \mathrm{CO}\end{aligned}$

A r

Ar $-\mathrm{O}_{2}-\mathrm{CO}$

w

$\begin{array}{ll}\mathrm{CH}_{4} & \\ & \\ & \mathrm{Log} \\ & \text { Scale }\end{array}$

\subsection{8}

1.20

0.41

2.33

1.19

0.33

1.412 .22

0.81

0.16

0.85

0.312 .18

$0.30 \quad 2.13$

$0.31 \quad 2.19$

0.68

0.20

0.82

0.17

3.08

NM

0.184 .95

0.69

0.20

0.115 .16

Linear $\left\{\begin{array}{llllll}0.06 & 0.18 & 4.95 & 0.69 & 0.11 & 5.16 \\ 0.02 & 0.12 & 4.59 & 0.53 & 0.08 & 5.15 \\ 0.05 & 0.15 & 4.40 & 0.54 & 0.08 & 4.53 \\ 0.50 & 1.46 & 4.05^{-11} & 1.93 & 0.69 & 4.14^{-11} \\ 0.15 & 1.02 & 3.79^{-11} & 3.68 & 0.60 & 4.13^{-11}\end{array}\right.$

Ratio for Linear Scale Measurements

\begin{tabular}{|c|c|c|c|c|}
\hline 15 & 16 & 18 & 28 & 32 \\
\hline 0.0116 & 0.0349 & 0.959 & 0.134 & 0.0213 \\
\hline 0.0039 & 0.0233 & 0.891 & 0.103 & 0.0155 \\
\hline 0.0110 & 0.0331 & 0.971 & 0.119 & 0.0177 \\
\hline 0.0121 & 0.0353 & 0.978 & 0.0466 & 0.0167 \\
\hline 0.0036 & 0.0247 & 0.915 & 0.0889 & 0.0145 \\
\hline
\end{tabular}

$10^{-11}$

$10^{-11}$

$10^{-11}$

$10^{-12}$

$10^{-12}$

$$
\begin{aligned}
& \mathrm{Ar}-\mathrm{O}_{2}-\mathrm{CO} \\
& \mathrm{Ar} \\
& \mathrm{Ar}-\mathrm{CH}_{4} \\
& \mathrm{Ar}-\mathrm{CH}_{4} \\
& \mathrm{Ar}
\end{aligned}
$$

O


BNWL -1208

TABLE 2. Change in Peak Height With and Without Liquid Nitrogen Trap Operating

\begin{tabular}{|c|c|c|c|c|c|c|c|}
\hline \multirow{2}{*}{ Date } & \multicolumn{2}{|c|}{ Without } & \multicolumn{2}{|c|}{ With } & \multirow{2}{*}{$\begin{array}{c}\text { Range } \\
\text { Amplification }\end{array}$} & & \multirow{2}{*}{$\begin{array}{l}\text { Reducti } \\
\text { At Mass } \\
\end{array}$} \\
\hline & 18 & 28 & 18 & 28 & & & \\
\hline $11-5$ & 73.0 & 7.52 & 8.08 & 5.08 & $10 \times 10^{-12 \mathrm{~A}}$ & & 9.0 \\
\hline $12-11$ & 5.30 & 1.50 & 2.70 & 0.92 & $10 \times 10^{-12}$ & & 2.0 \\
\hline $1-17$ & 8.83 & 6.06 & 1.40 & 7.50 & $10 \times 10^{-12}$ & $\begin{array}{l}\text { leak at } \\
\text { flange) }\end{array}$ & 6.3 \\
\hline
\end{tabular}

TABLE 3. Peak Height Ratio Versus Dilution

\begin{tabular}{|c|c|c|c|c|}
\hline Dilution* & $15 / 36$ & $16 / 36$ & $36 / 40$ & $15 / 16$ \\
\hline \multirow[t]{3}{*}{0} & 0.266 & 0.350 & $3.389 \times 10^{-3}$ & 0.762 \\
\hline & 0.257 & 0.338 & $3.507 \times 10^{-3}$ & 0.762 \\
\hline & 0.261 & 0.338 & $3.466 \times 10^{-3}$ & 0.774 \\
\hline 90.6 & 0.236 & 0.308 & $3.548 \times 10^{-3}$ & 0.767 \\
\hline 76.5 & 0.195 & 0.254 & $3.522 \times 10^{-3}$ & 0.765 \\
\hline 62.5 & 0.214 & 0.279 & $3.543 \times 10^{-3}$ & 0.769 \\
\hline 50.5 & 0.119 & 0.152 & $3.417 \times 10^{-3}$ & 0.784 \\
\hline 39.2 & 0.0942 & 0.131 & $3.457 \times 10^{-3}$ & 0.717 \\
\hline 27.6 & 0.0661 & 0.0903 & $3.473 \times 10^{-3}$ & 0.732 \\
\hline 22.6 & 0.0652 & 0.0902 & $3.465 \times 10^{-3}$ & 0.723 \\
\hline 10.9 & 0.0393 & 0.0578 & $3.444 \times 10^{-3}$ & 0.679 \\
\hline 0 & 0.270 & 0.348 & $2.902 \times 10^{-3}$ & 0.777 \\
\hline
\end{tabular}

* O dilution represents fulz concentration of $1000 \mathrm{ppm}$ methane in argon and the numbers represent percent of initial concentration. 
BNWL -1208

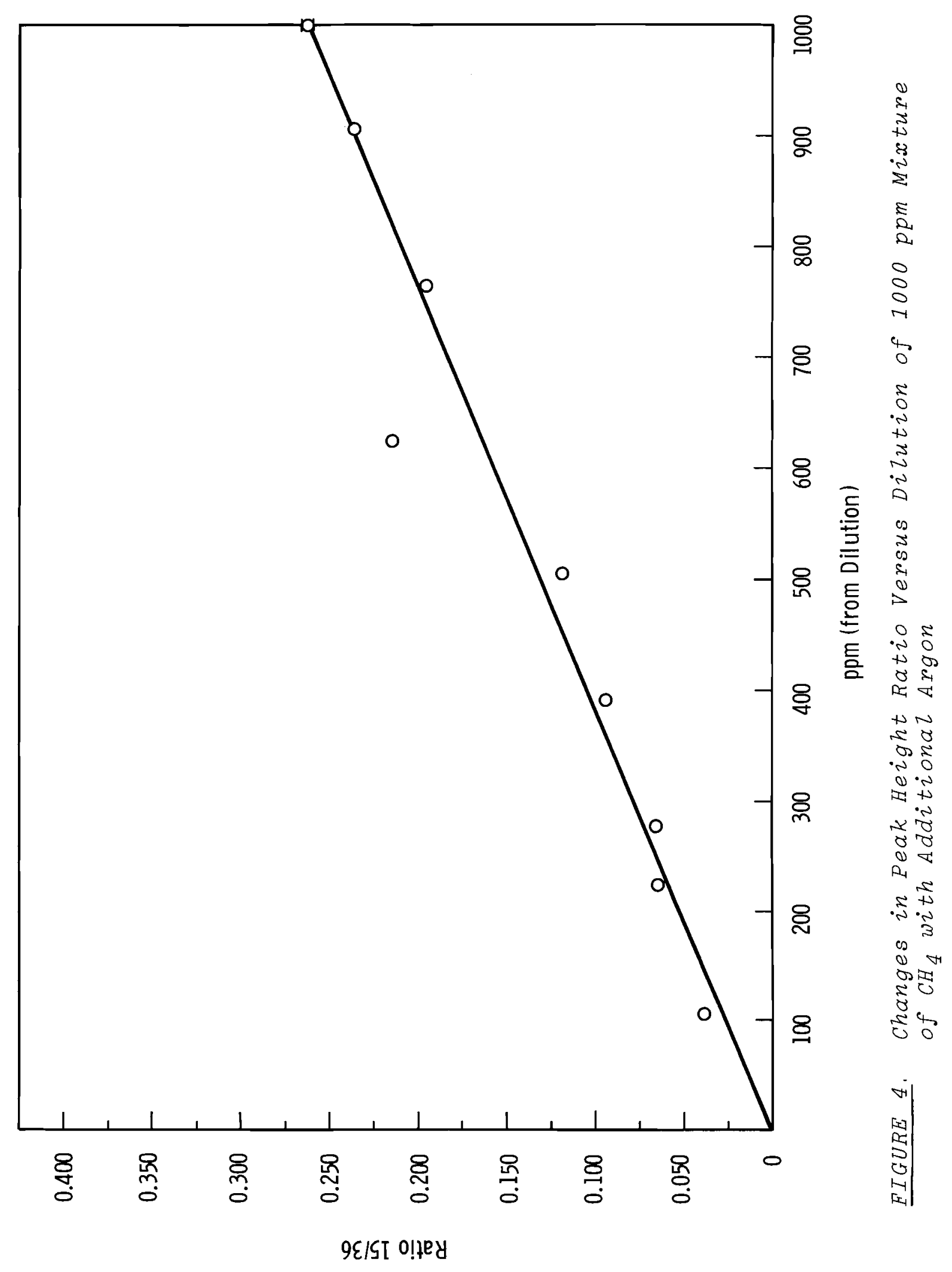


BNWL -1208

5
0
0
0
0
0
-1
0
5
8
5
0
0
5
4
0
0

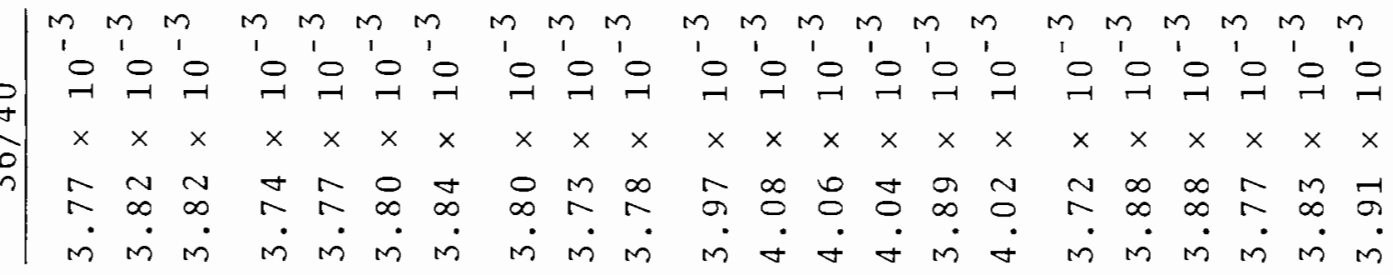

\%

- 0 (

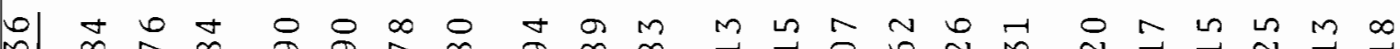

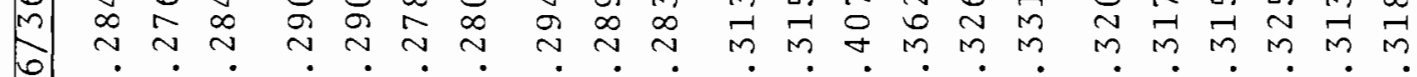

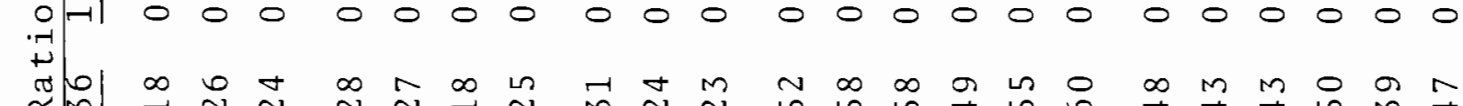

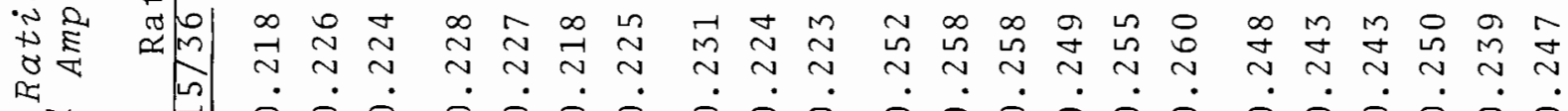

why

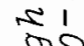

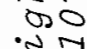

is

$\rightarrow \infty$

$\frac{a}{2} \pi$

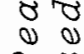

$\sin$

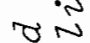

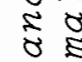

is

is

.

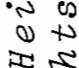

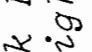

80

$a^{2}$

$\mathrm{D}^{2}$

40

$\operatorname{Rin}$

¿

\&

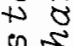

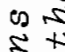

บ 2

$\left(\begin{array}{llll}n & 0 & 0 & 0\end{array}\right.$

$\dot{0} \dot{0} \dot{0} \dot{0}$

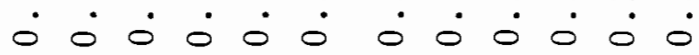

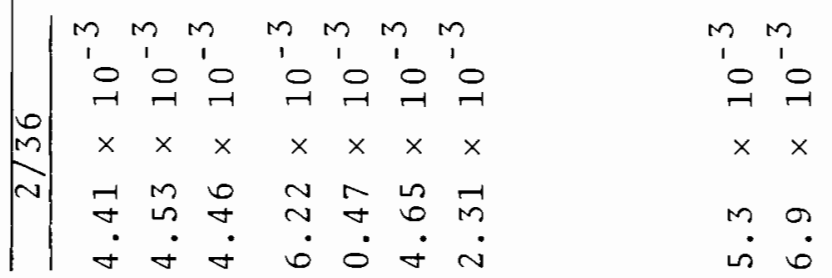

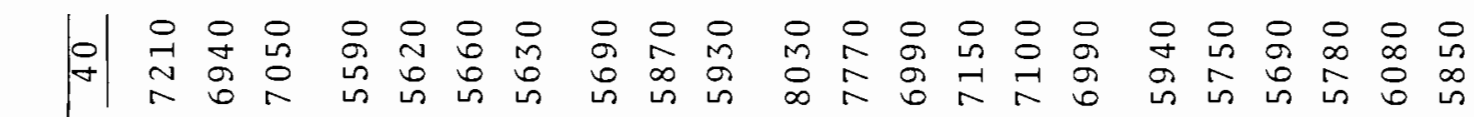

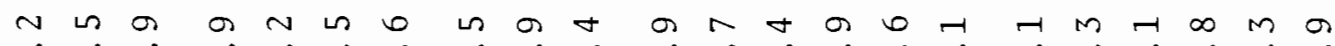

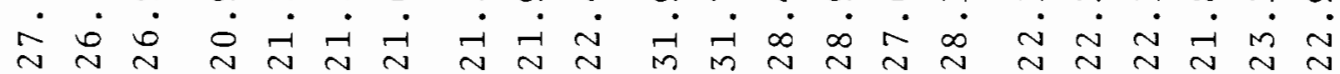

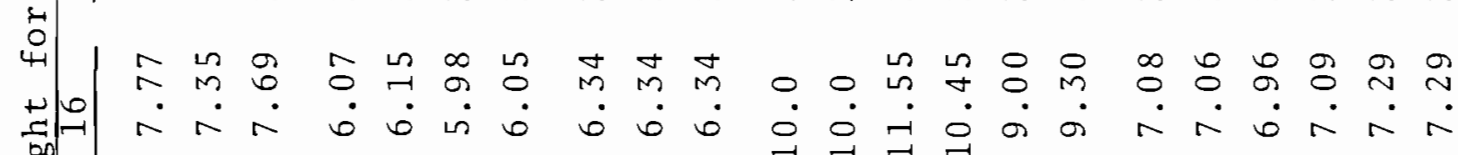
(1)

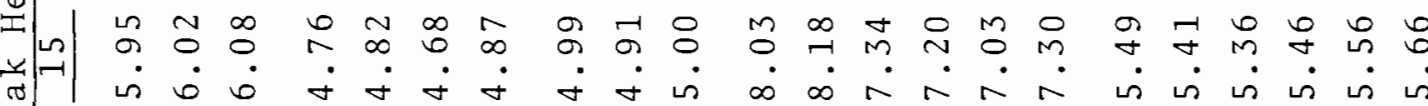

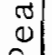

|

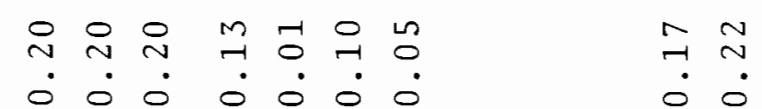

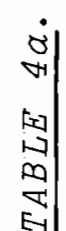

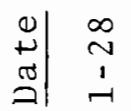

$\stackrel{9}{i}$

$\stackrel{0}{m}$

$M$ 
The stability of the instrument decreased over a period of time. The variation of the ion currents from the argon isotopes 36 and 40 , the measured peak heights, and the noise levels were used to monitor instrument stability. The data in Table $4 \mathrm{~b}$ do not contain the $36 / 40$ ratio because it was not measured. The subsequent data show the ratio to remain relatively constant from day to day even though the absolute peak heights change by more than $20 \%$. The data in Table 5 show the daily variability of the $36 / 40$ ratio to be about $1-3 \%$ with a longer term variability of greater magnitude. The variability of a group of daily readings is we 11 within the precision requirements for the instrument. The long term fluctuations are excessive. However, instrument operation normally includes an analysis of a standard sample. Compensations resulting from this analysis will cancel the effect of long term fluctuations.

Linearity of response at lower concentrations was established and the detection 1 imit was determined by measuring the ion currents produced from dilutions of a mixture of an original concentration of $100 \mathrm{ppm}$ methane or hydrogen. The results for methane are presented in Figure 5 and, for hydrogen, in Figure 6. Analysis of the data from which these figures were drawn indicated deviation about the line to be about $5 \mathrm{ppm}$. The limiting sensitivity for these impurities in argon appears to be $5 \mathrm{ppm}$ with an uncertainty of $5 \mathrm{ppm}$. These measurements were at room temperature. The limiting sensitivity would be expected to decrease with increasing temperature, since the resolution of the ions would decrease as their initial kinetic energy is increased. The detection limits and precisions obtainable with heated samples would therefore be poorer than 5 ppm.

\section{Operation with Sodium Vapor Bearing Samples}

With the instrument calibration and sensitivity established, the way was paved for testing the effects of sodium vapor laden 
BNWL - 1208

TABLE 4b. Constancy of Peak Heights and Peak Height Ratios of Tank Argon Sample (Electrometer range $3 x$ 10-10 Amp)

\begin{tabular}{|c|c|c|c|c|c|c|c|c|}
\hline \multicolumn{7}{|c|}{ Peak Height, in. } & \multicolumn{2}{|c|}{ Ratio } \\
\hline 14 & 16 & 17 & 18 & 28 & 32 & 36 & $18 / 36$ & $28 / 36$ \\
\hline 0.04 & 0.01 & 0.02 & 0.61 & 0.78 & 0.10 & 5.70 & 0.1070 & 0.1368 \\
\hline 0.04 & 0.01 & 0.02 & 0.60 & 0.76 & 0.11 & 5.66 & 0.1060 & 0.1343 \\
\hline 0.03 & 0.01 & 0.02 & 0.60 & 0.73 & 0.10 & 5.62 & 0.1068 & 0.1299 \\
\hline 0.06 & 0.01 & 0.02 & 0.59 & 0.72 & 0.09 & 5.61 & 0.1052 & 0.1283 \\
\hline 0.05 & 0.01 & 0.02 & 0.60 & 0.71 & 0.10 & 5.60 & 0.1071 & 0.1268 \\
\hline 0.03 & 0.01 & 0.02 & 0.60 & 0.71 & 0.10 & 5.58 & 0.1075 & 0.1272 \\
\hline 0.04 & 0.01 & 0.02 & 0.60 & 0.70 & 0.10 & 5.55 & 0.1081 & 0.1261 \\
\hline 0.03 & 0.01 & 0.02 & 0.59 & 0.70 & 0.10 & 5.51 & 0.1071 & 0.1270 \\
\hline 0.03 & 0.01 & 0.02 & 0.59 & 0.70 & 0.10 & 5.50 & 0.1073 & 0.1273 \\
\hline 0.04 & 0.01 & 0.02 & 0.59 & 0.70 & 0.10 & 5.50 & 0.1073 & 0.1273 \\
\hline 0.03 & 0.01 & 0.02 & 0.59 & 0.70 & 0.10 & 5.48 & 0.1077 & 0.1277 \\
\hline 0.03 & 0.01 & 0.02 & 0.59 & 0.69 & 0.10 & 5.46 & 0.1081 & 0.1264 \\
\hline 0.03 & 0.01 & 0.01 & 0.59 & 0.69 & 0.10 & 5.40 & 0.1093 & 0.1278 \\
\hline 0.04 & 0.01 & 0.02 & 0.57 & 0.70 & 0.11 & 5.42 & 0.1052 & 0.1292 \\
\hline 0.03 & 0.01 & 0.02 & 0.57 & 0.70 & 0.11 & 5.40 & 0.1056 & 0.1296 \\
\hline 0.04 & 0.01 & 0.02 & 0.58 & 0.70 & 0.11 & 5.38 & 0.1078 & 0.1301 \\
\hline 0.03 & 0.01 & 0.02 & 0.57 & 0.70 & 0.10 & 5.35 & 0.1065 & 0.1308 \\
\hline & & & 0.59 & 0.711 & & 5.513 & 0.1071 & 0.1290 \\
\hline & & & 0.0114 & 0.0237 & & 0.1010 & 0.00114 & 0.00278 \\
\hline & & & 1.93 & 3.33 & & 1.83 & 1.06 & 2.15 \\
\hline & & & 6.6 & 11.4 & & 6.1 & 0.47 & 4.4 \\
\hline
\end{tabular}


TABLE 5. Variation in 36/40 Ratio

\begin{tabular}{|c|c|c|c|c|}
\hline Date & * & Average & $\sigma$ & $\%$ \\
\hline $11-11$ & 6 & $3.660 \times 10^{-3}$ & 0.098 & 2.68 \\
\hline $1-9$ & 9 & $3.637 \times 10^{-3}$ & 0.1177 & 3.24 \\
\hline $1-10$ & 4 & $3.581 \times 10^{-3}$ & 0.1317 & 3.68 \\
\hline $1-14$ & 5 & $3.657 \times 10^{-3}$ & .0 .095 & 2.60 \\
\hline $1-16$ & 11 & $3.666 \times 10^{-3}$ & 0.0353 & 0.96 \\
\hline $1-17$ & 10 & $3.551 \times 10^{-3}$ & 0.0445 & 1.25 \\
\hline $1-24$ & 5 & $3.862 \times 10^{-3}$ & 0.0372 & 0.96 \\
\hline $1-28$ & 6 & $3.733 \times 10^{-3}$ & 0.0362 & 0.97 \\
\hline \multirow[t]{2}{*}{$1-28$} & 5 & $3.764 \times 10^{-3}$ & 0.0332 & 0.99 \\
\hline & 4 & $3.703 \times 10^{-3}$ & 0.0505 & 1.36 \\
\hline \multirow[t]{2}{*}{$1-29$} & 8 & $3.638 \times 10^{-3}$ & 0.0543 & 1.49 \\
\hline & 9 & $3.736 \times 10^{-3}$ & 0.0515 & 1.38 \\
\hline \multirow[t]{7}{*}{$1-30$} & 7 & $4.171 \times 10^{-3}$ & 0.0477 & 1.14 \\
\hline & 10 & $3.947 \times 10^{-3}$ & 0.0843 & 2.13 \\
\hline & 4 & $4.005 \times 10^{-3}$ & 0.0768 & 1.92 \\
\hline & 4 & $4.033 \times 10^{-3}$ & 0.1126 & 2.79 \\
\hline & 4 & $3.886 \times 10^{-3}$ & 0.0845 & 2.17 \\
\hline & 2 & $3.907 \times 10^{-3}$ & 435 & 1.11 \\
\hline & 3 & $3.927 \times 10^{-3}$ & 0.0309 & 0.79 \\
\hline $1-30$ & 8 & $3.809 \times 10^{-3}$ & 0.0502 & 1.32 \\
\hline \multirow[t]{3}{*}{$2-3$} & 6 & $3.740 \times 10^{-3}$ & 0.0659 & 1.76 \\
\hline & 25 & $3.675 \times 10^{-3}$ & 0.1008 & 2.74 \\
\hline & 10 & $3.74 \times 10^{-3}$ & 0.1353 & 3.62 \\
\hline & & $.75 \times 10^{-3}$ & -0.17 & +.9 \\
\hline
\end{tabular}

Number of scans measured. 
BNWL - 1208

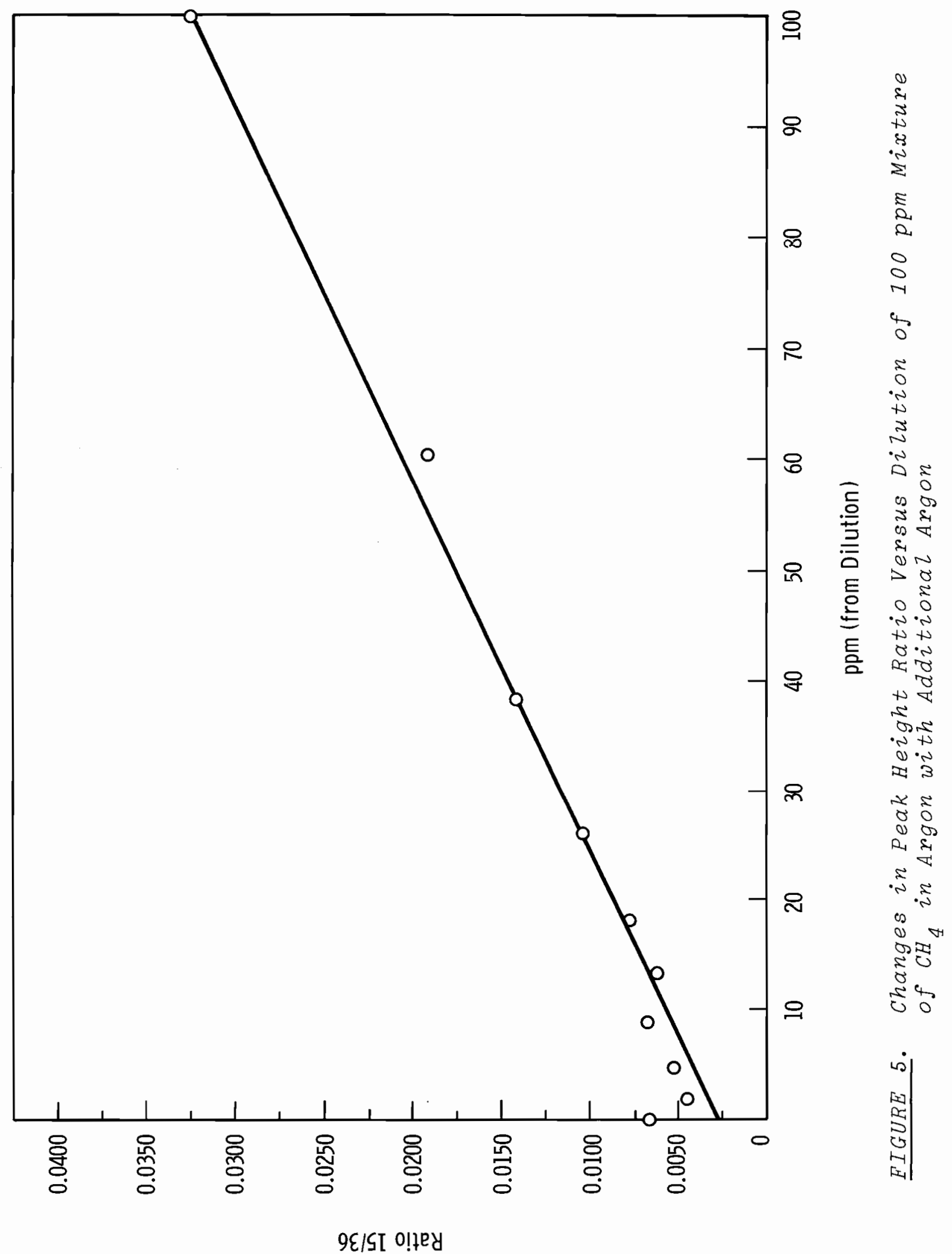


BNWL -1208

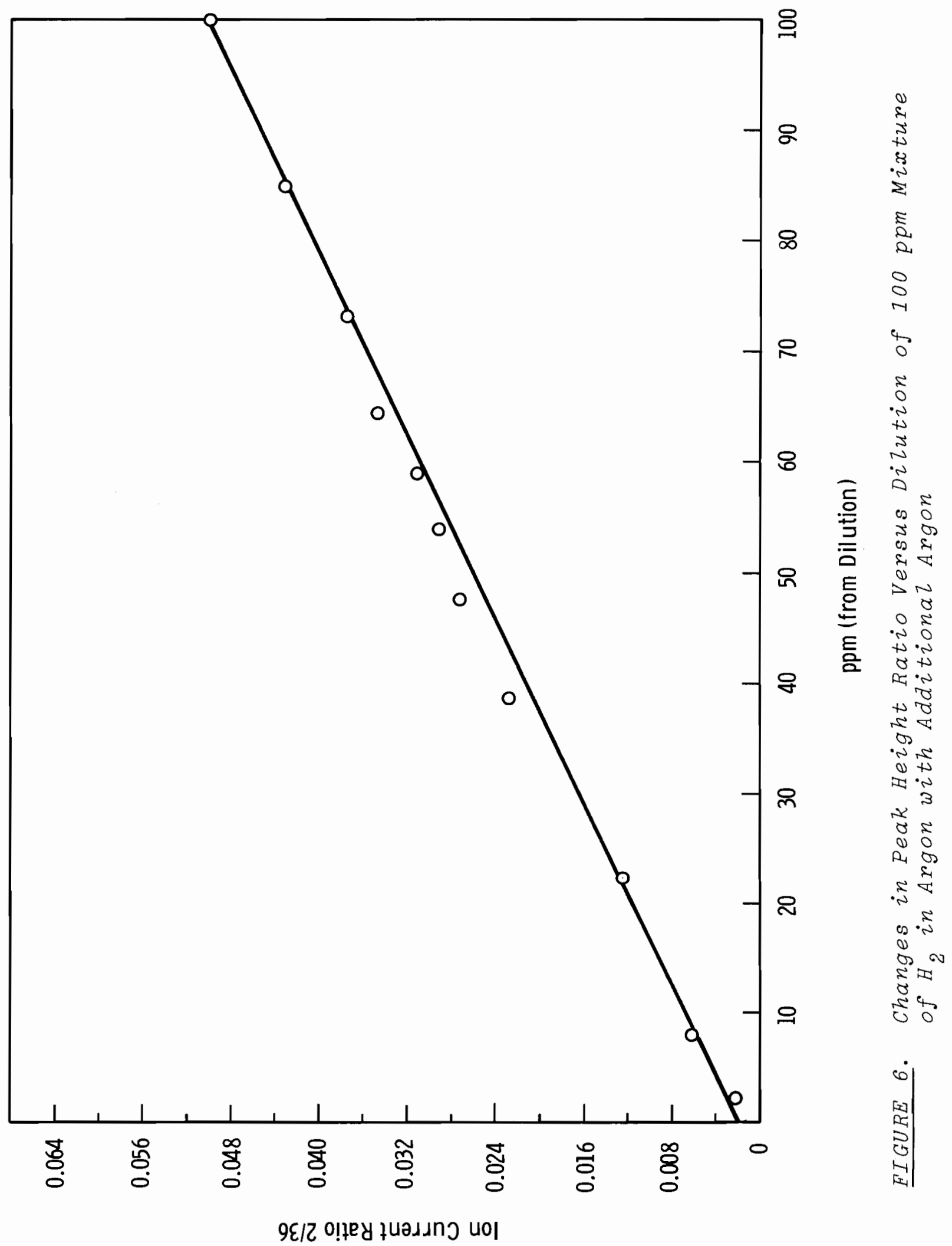


samples. The first test was to pass the gas mixture (1000 ppm methane in argon) through the sodium containing capsule, shown schematically in Figure 2. The gas was then passed through the sodium vapor trap and room temperature lines to the room temperature inlet system. The spectra were not visibly different, other than for peak heights, when the sample was passed through the sodium bearing capsule and through the bypass. There was no indication of the presence of sodium vapor (mass 23). The data are presented in Table 6. The decrease in methane peak height indicates that the reaction between $\mathrm{Na}$ vapor and $\mathrm{CH}_{4}$ can be measured readily. The data were compared by H. P. Maffei with kinetic data he had obtained on a recirculating system using gas chromatographic analysis for $\mathrm{CH}_{4}$. The calculated rate constants were in satisfactory agreement.

TABLE 6. Effect of Passing Methane-Argon Mixture Through Sodium containing capsuze

\begin{tabular}{|c|c|c|c|c|c|}
\hline \multirow[b]{2}{*}{ Date } & \multirow[b]{2}{*}{$\begin{array}{l}\text { Capsule } \\
\text { Temp, }{ }^{\circ} \mathrm{C}\end{array}$} & \multirow[b]{2}{*}{$\begin{array}{c}\text { Flow } \\
\mathrm{m} 1 / \mathrm{min}\end{array}$} & \multicolumn{3}{|c|}{ Methane } \\
\hline & & & $\begin{array}{l}\text { Bypass } \\
\text { Sample } \\
\end{array}$ & $\begin{array}{l}\text { Capsule } \\
\text { Sample } \\
\end{array}$ & $\begin{array}{c}\text { Exit } \\
\text { Concen, } \\
\text { ppm } \\
\end{array}$ \\
\hline $1-28$ & 25 & 51 & 0.223 & 0.222 & 1000 \\
\hline $1-29$ & 263 & 51 & 0.219 & 0.213 & 973 \\
\hline & 367 & 51 & 0.225 & 0.221 & 982 \\
\hline $1-30$ & 449 & 51 & 0.255 & 0.213 & 953 \\
\hline & 639 & 51 & 0.258 & 0.168 & 651 \\
\hline & & 20 & 0.258 & 0.116 & 450 \\
\hline & & 70 & 0.258 & 0.191 & 740 \\
\hline $2-3$ & 772 & 82 & 0.245 & 0.0252 & 103 \\
\hline & 754 & 62 & 0.245 & 0.0304 & 124 \\
\hline & & 42 & 0.245 & 0.0217 & 89 \\
\hline & & 17 & 0.245 & 0.0087 & 36 \\
\hline
\end{tabular}


The next test was to pass the sample through a heated 1 ine and heated inlet to determine whether sodium vapor would affect either the instrument or the analysis. Prior to these tests, it was necessary to clean and refill the capsule with sodium because of inlet line plugging. The sample system was set up so the gas could be introduced to the mass spectrometer via a continuous inlet. The sample could be brought to the inlet either by (1) a direct path, (2) through a sodium containing pot and through a trap and room temperature 1 ines, or (3) through the pot and then through heated 1 ines (Figure 2).

Significant instrument operating problems were encountered during these measurements and considerable operator attention was required. These problems included continued instability of instrument operation, sample line outgassing, and leaks. A portion of the instrument instability was found to come from the $300-\mathrm{V}$ power supply. Other circuits also contributed to the noise problem, but the magnitude of their contribution could not be definitely established. The instability was intermittent, thus permitting measurements to be made during the quiescent periods. The instabilities consisted of high noise levels, step shifts in signal when monitoring a single mass (see Figure 7), loss of regulation of the current of the ionizing electron beam (apparently related to magnet position), and shifts of magnet position or electron beam path in such a manner as to drastically reduce or completely lose the ion signal. Occasional erratic recycle was also experienced.

When heat was applied to the sample inlet, a drastic increase in background occurred. Approximately a week of heating and flushing with pure argon was required before the background subsided to usable levels. It was then necessary, in removing the contaminants introduced from the sample inlet and lines, to bake out the instrument itself. 
BNWL -1208

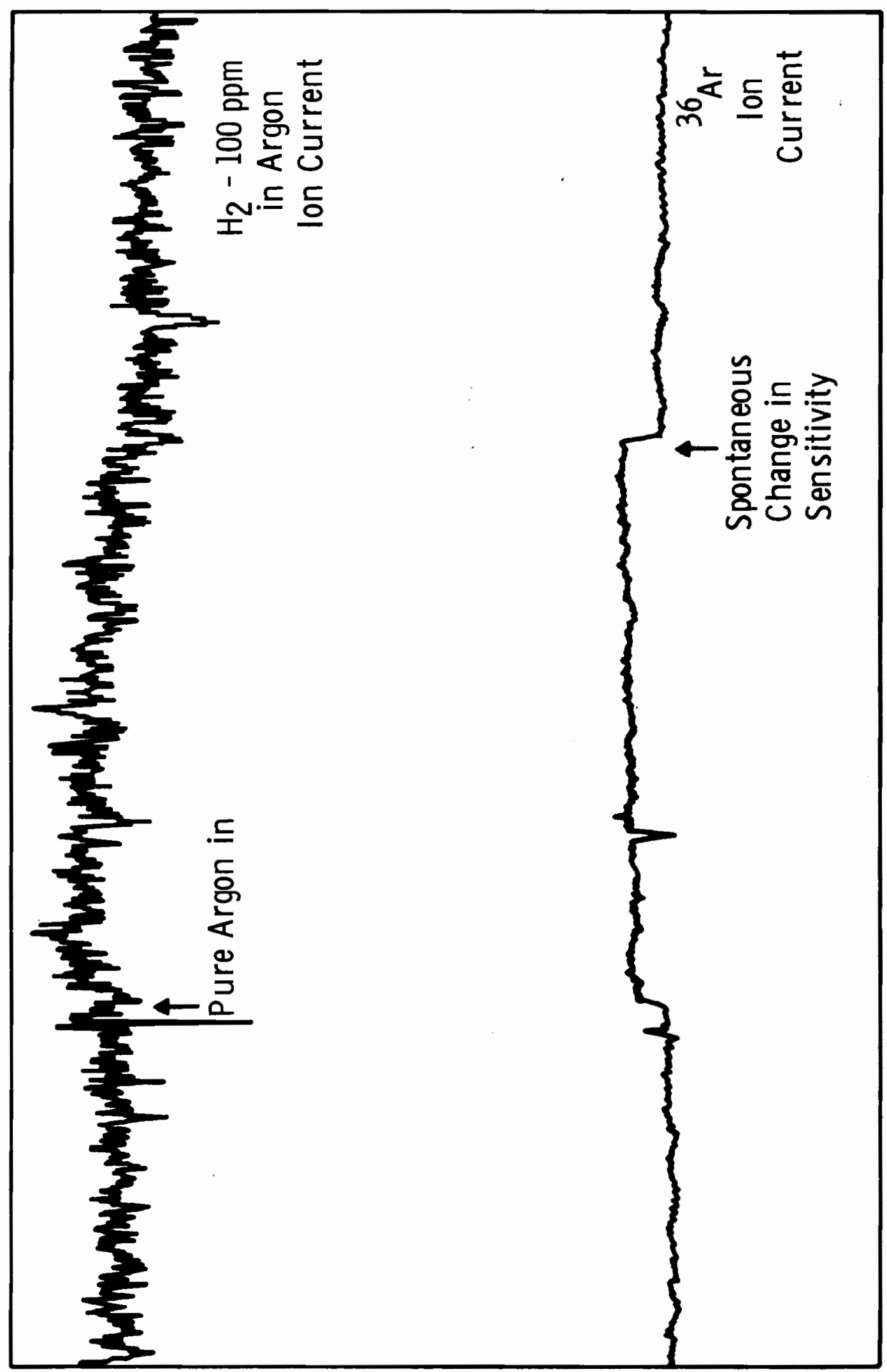

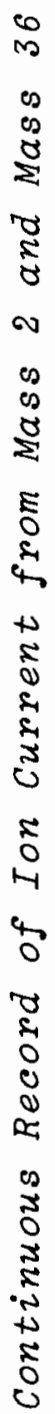

0
0
0
0
0
0
5
$0-1$ 
Measurements of pure argon were made, and two mixtures consisting of $\mathrm{Ar}-\mathrm{H}_{2}(100 \mathrm{ppm})$ and $\mathrm{Ar}-\mathrm{CH}_{4}(500 \mathrm{ppm})$ were introduced as samples in one of four ways by: (1) direct to cold inlet, (2) direct to hot inlet, (3) through heated pot containing sodium and then through the trap and cold lines to heated inlet, and (4) through the heated pot containing sodium and through heated lines to heated inlet. The results can be summarized for hydrogen and methane, respectively, as follows:

- The background contribution from the clean and cold spectrometer system without liquid nitrogen trapping is of the order of $300 \mathrm{ppm}$. Liquid nitrogen trapping reduces this to the order of $60 \mathrm{ppm}$ (Table 7). The background was so large when the heated inlet and sample lines were put into service that, even with liquid nitrogen trapping, the $100 \mathrm{ppm}$ hydrogen did not produce a measurable increase in the hydrogen peak. Two weeks of use of the heated sample lines did not reduce the background to the point where $100 \mathrm{ppm}$ was a measurable increment of the hydrogen peak (Figure 7). The gross background peak height was reduced somewhat. This background may come from any or all of several sources such as outgassing of the metals of construction, decomposition of traces of water or organic matter in the system, or transfer of $\mathrm{H}_{2}$ (formed from decomposing water vapor from the air on the outside of the hot lines) through the hot lines. When the inlet lines were allowed to cool, the background dropped back to its original low level (Table 7). The data indicate some hydrogen was released from the sodium when it was heated, but the major contribution was from the sampie system. 
TABLE 7. Reduction at Hydrogen Peak by Liquid Nitrogen Trapping

Ratio of

Ion Currents

Mass $2 / 36$

0.164

0.125

0.084

0.032

1.49

0.058
Ar - $1000 \mathrm{ppm} \mathrm{H}$, no $1 \mathrm{iq} \mathrm{N}_{2}$ in trap, cold inlet.

Ar (background), no $1 \mathrm{iq} \mathrm{N}_{2}$ in trap, cold inlet, background approx 3 times difference or approx $300 \mathrm{ppm}$.

Ar - $100 \mathrm{ppm} \mathrm{H}$, $1 \mathrm{iq} \mathrm{N}_{2}$ in trap, cold inlet. Ar (background), liq $\mathrm{N}_{2}$ in trap, cold inlet, background approx 0.6 times difference or approx $60 \mathrm{ppm}$.

Ar (background), liq $\mathrm{N}_{2}$ in trap, hot inlet.

Ar (background), 1 iq $\mathrm{N}_{2}$ in trap, inlet cooled for $18 \mathrm{~min}$, hot inlet 25 times cooled inlet.

- A mixture containing 500 ppm methane in argon showed a measurable degree of decomposition when passed through the sodium containing pot at $1200^{\circ} \mathrm{F}$ but not at $1000^{\circ} \mathrm{F}$. A mixture containing 1000 ppm methane underwent measurable decomposition at both temperatures, probably because the reaction was second order and its rate increased with the square of the concentration. There was no measurable difference in the methane concentration when the sample from the $1200^{\circ}$ experiment was carried from the pot to the mass spectrometer inlet in a heated line (700 to $\left.850^{\circ} \mathrm{F}\right)$, or when passed through lines at room temperature to the heated inlet. There was a very small and uncertain indication of a peak at mass 23 when the heated 1 ines and inlet were used. A measurable peak should have been observed if sodium vapor had been reaching the analyzer. When the temperature of the lines was raised in an effort to raise the sodium concentration of the gas reaching the inlet system, the sample splitting capillary plugged with 
sodium. The inlet system and lines were cooled and the inlet system dismantled. The main sample stream was found to have carried considerable sodium into the space where the capillary sample splitter was installed. However, no metallic sodium was apparent beyond the capillary. At $700^{\circ} \mathrm{F}, 200$ to $300 \mathrm{ppm}$ sodium would be in the argon and, at the estimated 850 to $900^{\circ} \mathrm{F}$ temperature of the inlet, it would be approximately $1000 \mathrm{ppm}$. The heated line apparently had delivered a sodium containing gas stream to the sample splitter of the inlet system, but the sodium failed to accompany the gas into the mass spectrometer at its full concentration.

The reason for the retention of sodium was not apparent. That the sodium did not appear to reach the spectrometer in significant concentrations, however, would indicate that the current series of experiments has not firmly established the ability of the instrument to handle samples containing significant concentrations of sodium vapor.

One indication of possible adverse effects was the development of a broad peak between masses 28 and 36 after the introduction of sodium bearing samples. However, electronic difficulties have prevented firm assignment of this change to the presence of sodium. The presence of sodium as the cause would seriously interfere with the detection of low concentrations of oxygen, while difficulties due to electronics should be correctable. 
BNWL -1208

\section{DISCUSSION}

The mass spectrometer appeared to offer the advantages of (1) ability to accept high temperature samples and (2) ability to detect the presence of unknown or unexpected impurities and facilitate their identification. The results of this evaluation indicate serious problems connected with the successful introduction of high temperature samples into the mass spectrometer. The first of these involves the design of the inlet system, molecular leak, etc. to prevent the occurrence of sample fractionation. A second problem is the high background created by the heated sample line.

Some doubt remains concerning the suitability of the instrument for the identification function in the presence of sodium vapor. There are some indications that the performance of the instrument is adversely affected by the sodium vapor when operated with a heated sampling system. If operated with a room temperature sampling system, sufficient sodium is removed to permit the detection and possible identification of impurities.

Use of the instrument, once it has been correctly adjusted, is routine. Measurement of a flowing sample would consist of starting the recorder chart drive and the timing scan, and resetting the electrometer range switch as needed to keep the record on scale, then measuring the peak heights from the recorder chart and calculating the concentration from calibration data. As an alternate procedure, the ion current ratios could be measured by appropriately setting the mass selector potentiometer and then recording the ion currents on the recorder chart.

Should the instrument go out of adjustment, resetting of magnet position, ion focus control, and ionizing electron beam 
energy may be required to bring it back. These operations are not difficult but require some experience and patience and may consume substantial time.

It appears feasible to automate the instrument and place it under computer control. By using the instrument to check a standard sample routinely, any departure from acceptable performance could be interpreted as a warning that attention is required. A suitably trained operator then could make the necessary adjustments. Reliable operation of the mass spectrometer requires more knowledge and familiarity with the instrument than can be expected from the normal reactor operator. Therefore, the instrument does not appear to be a desirable choice for monitoring the trace impurities in the sodium cover gas of the FFTF. A further evaluation of the instrument as a research tool is planned. It will be installed on an operating sodium cover gas system in parallel with a gas chromatograph and operated for a period of time. The information obtained will be correlated with chromatographic measurements and other available data to determine the usefulness of the instrument in the sodium technology RED programs. 
BNWL -1208

\section{REFERENCES}

1. C. J. Foley. Unpublished Data. Conceptual System Design Description for Inert Gas Receiving and Processing System No. 82, A-0016-R2. Battelle-Northwest, Richland, Washington, September 4, 1968. (Preliminary Report)

2. H. P. Maffei. Preliminary FFTF Cover Gas Impurity Specifications, Methane and Carbon Monoxide Impurity Levels in Argon; Oxygen Levels in Nitrogen, BNWL-1143. Battelle-Northwest, Richland, Washington, 1969. 


\section{DISTRIBUTION}

No. of

Copies

OFFSITE

\section{AEC Chicago Patent Group}

G. H. Lee

AEC Division of Reactor Development and Technology

M. Shaw, Director, RDT

Asst Dir for Nuclear Safety

Analysis $\&$ Evaluation Br, RDT:NS

Environmental \& Sanitary Engrg Br, RDT:NS

Research \& Development Br, RDT:NS

Asst Dir for Plant Engrg, RDT

Facilities $\mathrm{Br}$, RDT:PE

Components $\mathrm{Br}$, RDT:PE

Instrumentation \& Control Br, RDT:PE

Liquid Metal Systems Br, RDT:PE

Asst Dir for Program Analys is, RDT

Asst Dir for Project Mgmt, RDT

Liquid Metals Projects Br, RDT:PM

FFTF Project Manager, RDT:PM (3)

Asst Dir for Reactor Engrg, RDT

Control Mechanisms Br, RDT:RE

Core Design Br, RDT:RE (2)

Fuel Engineering $\mathrm{Br}$, RDT:RE

Fue 1 Handling $\mathrm{Br}$, RDT: RE

Reactor Vessels $\mathrm{Br}, \mathrm{RDT}: \mathrm{RE}$

Asst Dir for Reactor Tech, RDT

Coolant Chemistry Br, RDT:RT

Fuel Recycle Br, RDT:RT

Fuels \& Materials Br, RDT:RT

Reactor Physics Br, RDT:RE

Special Technology Br, RDT:RT

Asst Dir for Engrg Standards, RDT

EBR-II Project Manager, RDT:PM

AEC Division of Technica1 Information Extension

AEC Idaho Operations Office

Nuclear Technology Division

C. W. Bills, Director

AEC San Francisco Operations office

Director, Reactor Division 
BNWL - 1208

No. of

Copies

4

1

7

1

1

1

5

1

AEC Site Representatives

Argonne National Laboratory

Atomics International

Atomic Power Development Assoc.

General Electric Co.

3 Argonne National Laboratory

R. A. Jaross

LMFBR Program office

N. J. Swanson

Atomic Power Development Assoc.

Document Librarian

Atomics Internationa 1

FFTF Program office

Liquid Metal Information Center

J. J. Droher (2)

Babcock \& Wilcox Co.

Atomic Energy Division

S. H. Esleeck

G. B. Garton

Bendix Corporation

160 Elvira St.

Livermore, California 94550

K. L. Montgomery

BNW Representative

N. A. Hill (ZPR III)

Combustion Engineering

1000 MWe Follow-On Study

W. P. Staker, Project Manager

Genera1 Electric Company

Advanced Products Operation

Kar1 Cohen (4)

Nuclear Systems Programs

D. H. Ahmann 
No. of

Copies

2

1

Stanford University

Nuclear Division

Division of Mechanical Engrg

R. Sher

1 United Nuclear Corporation

Research and Engineering Center

R. F. DeAngelis

10

15

Bechte1 Corporation

Westinghouse Electric Corporation

J. J. Teachnor, Project Administrator, FFTF

Atomic Power Division

Advanced Reactor Systems

J. C. R. Ke11y

ONSITE-HANFORD

1

Bechte1 Corporation

M. O. Rothwell (Richland)

1

Westinghouse Electric Corporation

R. Strzelecki (Richland)

1

AEC, Asst Director RDT

Pacific Northwest Programs

1

AEC Chicago Patent Group

R. K. Sharp 
No. of

Copies
AEC RDT Site Representative

P. G. Holsted (3)

AEC Richland Operations Office

J. M. Shivley

Battelle Memorial Institute

Battelle-Northwest

E. R. Astley

G. B. Barton (5)

J. C. Cochran

D. L. Condotta

R. L. Dillon

J. F. Erben

E. A. Evans

C. J. Foley

F. C. Gronemeyer

P. L. Hofmann

H. E. Little

J. J. McCown

W. B. McDonald

J. S. McMahon

W. E. Roake

F. A. Scott

D. W. Shannon

R. J. Squires

W. R. Wykoff

Legal - 703 Building

Lega 1 - ROB, 221-A

Technical Information (5)

Technical Publications (2)

FFTF File, 703 Building (10)

FFTF TPO (1ist "T") (3) 